\title{
Nachruf auf Birgit Rommelspacher
}

Birgit Rommelspacher ist am 16. April 2015 völlig unerwartet und viel zu früh in Frankfurt am Main gestorben. Birgit Rommelspacher, geboren in Oberschwaben, studierte zunächst Psychologie, arbeitete u.a. am Deutschen Jugendinstitut in München und ging Anfang der 1980er Jahre nach Berlin. Dort war sie lange Zeit Professorin für Psychologie an der Alice Salomon Hochschule, setzte sich nachhaltig für die Institutionalisierung von Diversity Studies und für die Etablierung gesellschaftskritischer Forschung und Lehre ein und baute u.a. den Masterstudiengang Soziale Arbeit als Menschenrechtsprofession mit auf. In den Fachdebatten zu Rechtsextremismus, Rassismus, Antisemitismus, Anti-Islamismus, Geschlechterverhältnissen, Heteronormativität/Homosexualität, Migration, Menschenrechten und Erinnerungskultur setzte sie wichtige Impulse. Eine zentrale Frage, die sie bewegte, bezog sich auf das Verhältnis zwischen machtvoll unterdrückenden Strukturen/Diskursen und den Denk- und Handlungsmustern von individuellen Subjekten: Wie werden Individuen und Gruppen beeinflusst? Weshalb und in welcher Weise reproduzieren sie asymmetrische Machtverhältnisse? Welche Funktionen und Mechanismen wirken dabei? Aber eben auch: Wo lassen sich Widersprüchlichkeiten entdecken, welche Möglichkeiten entwickeln sich für die Subjekte, um sich gegen solche Verhältnisse zu wenden und wie lässt sich Widerständigkeit unterstützen?

Birgit Rommelspacher war nicht nur eine Wissenschaftlerin, die sich mit kritischen Beschreibungen begnügte. Sie war immer zugleich politisch engagiert. Als öffentliche Intellektuelle war sie in vielen Initiativen und Netzwerken aktiv, verband wissenschaftliche Arbeit mit politischen Fragen und umgekehrt. Dabei kam sie zu neuen und kreativen Lösungen. So hat sie bereits in den 1990er Jahren den Begriff Dominanzkultur für die (Fach-) Debatten in Deutschland vorgeschlagen und entfaltet und damit „ein Ensemble gesellschaftlicher Praxen und gemeinsam geteilter Bedeutungen“ in den Blick genommen, das durch „spezifische Kategorien von Über- und Unterordnung“ gekennzeichnet ist (Rommelspacher 1995, S. 22f.). Dabei handelt es sich - so Birgit Rommelspacher - um ein „Geflecht verschiedener Machtdimensionen (...), die in Wechselwirkung zueinander stehen“ (ebd., S. 23) und bei denen nicht mehr „eindeutig zu bestimmen“ ist, „,welches der Hauptwiderspruch ist und welches die Nebenwidersprüche“ (ebd.) sind. Sie hat also schon Mitte der 1990er Jahre eine Theorieskizze entworfen, die heute unter Begriffen wie Intersektionalität oder Interdependenz firmieren.

Kolleginnen, Freundinnen und Mitstreiterinnen von Birgit Rommelspacher haben in den letzten Tagen gerade eine Festschrift fertiggestellt, um aus Anlass ihres 70. Geburtstags ihr bisheriges Werk zu würdigen. Die Herausgeberinnen sprechen im Entwurf der Einleitung pointiert von einer „Zwischenbilanz“, da Bir-

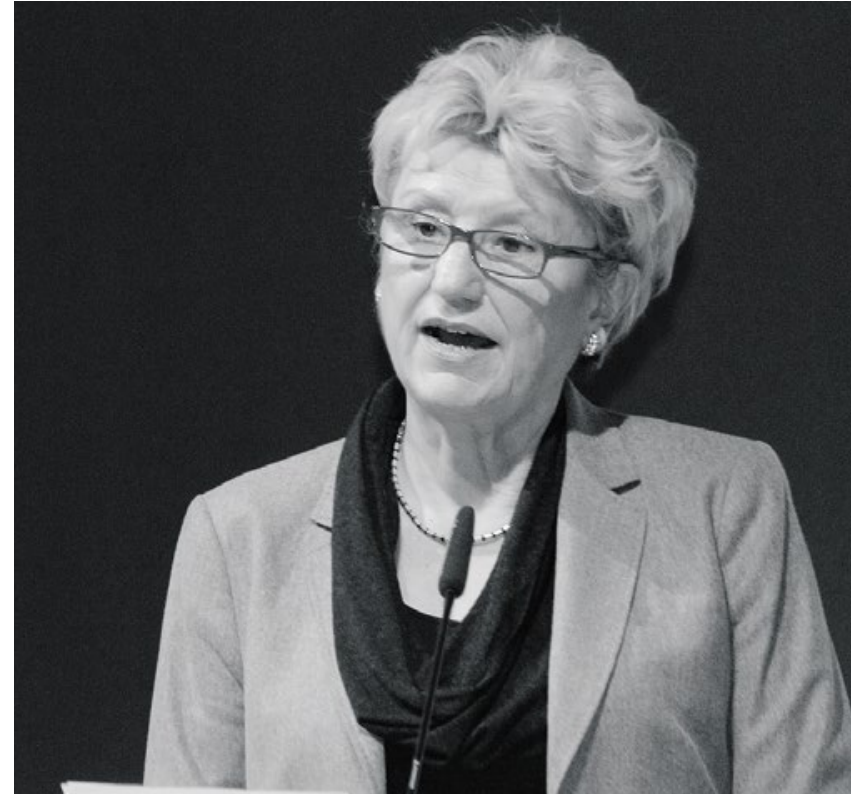

BIRGIT ROMMELSPACHER

Foto: Stephan Röhl / Heinrich-Böll-Stiftung. Das Bild steht unter einer Creative Commons Lizenz.

git Rommelspacher viele Pläne hatte und mit großer Freude immer wieder neue Aktivitäten entwickelte: Ein Buchprojekt, in dem u.a. der christlich-säkulare Diskurs zu Islam und Judentum in kritischer Perspektive untersucht wird, stand kurz vor dem Abschluss und war bereit für die Publikation; an der Universität Frankfurt hatte sie gerade mit viel Schwung und Leidenschaft eine Seniorprofessur für Sozialpsychologie angetreten.

Mit ihrem plötzlichen Tod hatte niemand gerechnet. Birgit Rommelspacher hinterlässt eine große Lücke. In ihrem Werk steckt jedoch die Herausforderung, in ihrem Sinne weiter zu gehen. Das sollten wir tun. Sie hat uns viele Denkinstrumente und Hinweise gegeben, wichtige Grundsteine gelegt; dass der Weg bislang ein wenig einfacher war, haben wir ihr zu verdanken.

\section{Rudolf Leiprecht/Helma Lutz}

Literatur: Rommelspacher, Birgit (2005). Dominanzkultur. Texte zu Fremdheit und Macht. Berlin 